\title{
ENSINO DE ENFERMAGEM: QUEM DISCUTE E O QUE É DISCUTIDO?
}

Eduardo Borba Neves ${ }^{1}$, Mariana Mendonça Zanin² ${ }^{2}$ Robson Douglas de Oliveira² ${ }^{2}$ Érica de Oliveira Borba ${ }^{3}$, Luiz Alberto Gasparin², Vera Lucia Manica ${ }^{2}$

\begin{abstract}
RESUMO: O presente trabalho teve por objetivo descrever de que forma o Ensino de Enfermagem vem sendo discutido e o perfil dos autores que discutem esse tema. A pesquisa de revisão sistemática foi operacionalizada por meio da busca eletrônica de artigos indexados na base de dados SciELO, por meio do descritor "Ensino de Enfermagem", em "Assunto", no dia 15 de abril de 2010. Foram analisados todos os artigos encontrados, perfazendo um universo de 11 trabalhos. Os resultados sugerem que a pesquisa científica na área do Ensino de Enfermagem ainda é pouco desenvolvida e que os autores dos artigos analisados possuem formação acadêmica adequada à reflexão neste tema. O principal foco dos estudos são as mudanças sofridas ou, em alguns estudos, a necessidade de mudanças no Ensino de Enfermagem para atender ao contexto econômico, político e social e as evoluções das políticas públicas de saúde ao longo do tempo.
\end{abstract}

PALAVRAS-CHAVE: Ensino de enfermagem; Educação; Saúde.

\section{NURSING TEACHING: WHO DISCUSSES WHAT IS DISCUSSED?}

ABSTRACT: This work aims to describe the way in which Nursing Teaching is being discussed and the profile of the authors who discuss it. The literature search was undertaken via the Internet, searching for articles indexed in the SciELO database, with the search term 'Nurse Teaching' as subject, on April 15th 2010. All 11 articles found were analyzed. The results suggest that scientific research in the area of Nurse Teaching is under-developed but that the authors of the articles analyzed possess appropriate academic backgrounds for reflecting on the subject. The main focus of the studies is the changes which have happened, and, in some studies, the necessity for changes to keep up with the economic, political and social context and changes in public health policy over time.

KEYWORDS: Nursing Teaching; Education; Health.

\section{ENSEÑANZA DE ENFERMERÍA: ¿QUIÉN DISCUTE Y LO QUÉ ES DISCUTIDO?}

RESUMEN: El presente trabajo tuvo por objetivo describir de que modo la Enseñanza de Enfermería está siendo discutida y el perfil de los autores que discuten ese tema. La investigación de revisión sistemática fue operacionalizada por medio de la búsqueda electrónica de artículos indexados en la base de datos SciELO, por medio del descriptor "Enseñanza de Enfermería", en "Asunto", el día 15 de abril de 2010. Fueron analizados todos los artículos encontrados, tolalizando un universo de 11 trabajos. Los resultados sugieren que la investigación científica en área de Enseñanza de Enfermería todavía es poco desarrollada y que los autores de los artículos analizados poseen formación académica adecuada a la reflexión neste tema. El principal foco de los estudios son las cambios sufridas o, en algunos estudios, la necesidad de cambios en la Enseñanza de Enfermería para atender al contexto económico, político y social y las evoluciones de las políticas públicas de salud a lo largo del tiempo.

PALABRAS CLAVE: Enseñanza de enfermería; Educación; Salud.

${ }^{1}$ Fisioterapeuta. Doutor em Engenharia Biomédica. Professor do Centro Universitário Campos de Andrade.

${ }^{2}$ Enfermeiro. Especialista em Enfermagem do Trabalho. Professor do Centro Universitário Campos de Andrade.

${ }^{3}$ Enfermeira. Especialista em Biossegurança Hospitalar. Chefe do Serviço de Enfermagem do Hospital Geral de Curitiba.

Autor correspondente:

Eduardo Borba Neves

Centro Universitário Campos de Andrade

R. Alcides Terézio de Carvalho 139, casa 15 - 81520-230 - Curitiba-PR-Brasil

E-mail: borbaneves@hotmail.com

Recebido: 04/08/10

Aprovado: 09/05/11

Cogitare Enferm. 2011 Abr/Jun; 16(2):348-52 


\section{INTRODUÇÃO}

O ensino de Enfermagem no país passou por várias fases de desenvolvimento ao longo dos anos, tendo como influência direta de cada mudança o contexto histórico da Enfermagem e da sociedade brasileira. Consequentemente, o perfil dos enfermeiros apresenta significativas mudanças em decorrência das transformações no quadro político-econômico-social da educação e da saúde no Brasil e no mundo ${ }^{(1)}$.

No Brasil foram realizadas várias reformulações curriculares ao longo dos anos, no que se refere às mudanças nas organizações de ensino em saúde. A partir dos anos 90, com a promulgação da Lei de Diretrizes e Bases da Educação Nacional (Lei n. 9.394/96) foram aprovadas as Diretrizes Curriculares Nacionais que preconiza a formação profissional com cunho generalista, humanista, crítico e reflexivo, orientada por princípios éticos em seus diferentes níveis de atenção ${ }^{(2)}$.

O processo de ensino-aprendizagem tem sido estudado sob óticas diversas, frequentemente pautadas em cenários compostos pela análise da interdependência entre questões políticas e sociais e seus desdobramentos na educação e formação de recursos humanos nas diversas áreas profissionais ${ }^{(3)}$.

De certo modo, determinadas repercussões educacionais, resultantes da influência dos modelos políticos e econômicos e de suas flutuações, parecem ser mais evidentes do que outras. Exemplificando, podemos apontar a desqualificação progressiva do ensino brasileiro, nos diferentes níveis, como consequência do desinteresse político, da desorganização social, e em menor escala, do atual momento econômico, como fatores inegavelmente percebidos por diversos segmentos da nossa sociedade ${ }^{(3)}$. Isto inclui o ensino nos diversos níveis da Enfermagem.

Entretanto, em meio à globalização, nota-se que o acesso a qualquer tipo de informação tornou-se facilitado pela internet, televisão, rádio, jornais e outros meios de comunicação. A população, mesmo diante de tantas informações, não sabe, na maioria das vezes, como utilizá-las e nem interpretá-las. Dessa forma, percebe-se a necessidade dos docentes e também dos alunos de tornar sujeitos ativos, críticos e criativos na transformação das informações em conhecimentos importantes e necessários para o desenvolvimento escolar e comunitário(1).

Nesta perspectiva, gestores, educadores e associações de classe do setor brasileiro da educação promoveram muitos debates na busca de repensar os fazeres educacionais ${ }^{(4)}$. Estas discussões são necessárias no âmbito da educação em Enfermagem, visto que os cursos têm se multiplicado pelo país e o número de enfermeiros formados tem crescido muito, tornando imprescindível a qualidade da formação através da reflexão, análise e avaliação de seus formadores ${ }^{(4)}$.

Observa-se também dificuldade de ensino e aprendizagem no nível médio de Enfermagem, principalmente no que se refere à competência e habilidade de comunicação e relacionamento interpessoal, considerados parte integrante do cuidar, portanto, instrumentos de trabalho do enfermeiro e de sua equipe ${ }^{(5)}$.

O docente, como uma das figuras centrais do processo de mudança curricular, e que tem sua adesão compromissada, necessita romper com práticas anteriores, em geral mais tradicionais, reestruturando-as. Essa mudança passa pela capacitação pedagógica com valorização dos atos reflexivos, o que propicia um maior conhecimento do campo da educação, permitindo o repensar e o fazer docente com criticidade, criatividade e inovação, à luz de um novo paradigma ${ }^{(2)}$.

A liberdade humana é um ponto de partida para a educação do aluno de Enfermagem em formação e prática. A educação deve proporcionar um pensamento crítico; mudar o foco do ensino: do treinamento para a educação, da técnica para a compreensão, do conteúdo estrito para a tomada de consciência crítica. Ao docente cabe ainda ocupar-se com o conteúdo do aprendizado do aluno no seu processo de educação, que não consiste apenas em ministrar aulas diante de um aluno passivo. Professor e aluno trabalham em aliança, onde o conteúdo é a matéria prima da aprendizagem e o que é feito com o conteúdo depende do processo experimentado pela pessoa do aluno ${ }^{(6)}$.

Aliado a isto, existe a necessidade de mudanças nas políticas sociais, entre as quais, as da saúde que se traduzem nas propostas de reformas, quando o Estado brasileiro passou a redefinir diretrizes e projetos para essa área. Isso significa que as universidades precisam reorientar o ensino, no sentido de formar profissionais capazes de responder à nova tendência ${ }^{(6)}$. Neste sentido, o presente trabalho teve por objetivo descrever de que forma o ensino de Enfermagem vem sendo discutido e o perfil dos autores que discutem esse tema.

\section{METODOLOGIA}

A pesquisa de revisão sistemática foi operacionalizada por meio da busca eletrônica de artigos indexados na base de dados Scientific Eletronic Library Online 
(SciELO), por meio do descritor "Ensino de Enfermagem", em "Assunto", no dia 15 de abril de 2010. Todos os artigos encontrados foram analisados.

A metodologia SciELO permite a publicação eletrônica de edições completas de periódicos científicos, a organização de bases de dados bibliográficos e de textos completos, a recuperação de textos por seu conteúdo, a preservação de arquivos eletrônicos e a produção de indicadores estatísticos de uso e impacto da literatura científica, garantindo a visibilidade e a acessibilidade da literatura científica. Espelhando a produção científica na internet ${ }^{(7-8)}$.

Os artigos encontrados foram analisados segundos cinco indicadores: 1) a formação dos autores dos artigos, 2) a instituição a qual cada pesquisa estava ligada, 3) o objeto de estudo, 4) as ferramentas utilizadas para melhorar o ensino e 5) as principais críticas ao ensino de enfermagem. Acredita-se que a análise destes indicadores possibilita uma visão da produção científica na área do ensino de Enfermagem no Brasil.

\section{RESULTADOS}

$\mathrm{Na}$ busca eletrônica foram encontrados 11 artigos publicados no período de 1993 a 2009, todos em português. As metodologias utilizadas foram estudo qualitativo, pesquisa descritiva de caráter exploratório e revisões bibliográficas dos artigos.

De acordo com o primeiro indicador analisado nos artigos (formação dos autores) houve um total de 34 autores, sendo sua formação constituída de $82 \%$ (28) de Enfermeiros, sendo 70\% (24) doutores em Enfermagem, 6\% (02) mestres em Enfermagem, 3\% (01) especialista em Enfermagem, 3\% (01) doutoranda em Enfermagem, 3\% (01) pós-doutorando em Enfermagem. Os demais pertenciam a diversas categorias, a saber: um mestre em farmácia, um mestre em ciências da nutrição, um assistente social, um doutor em psicologia e um doutor em sociologia. Ainda em relação aos autores, verificou-se que 94\% (32) eram do sexo feminino; houve predomínio de trabalhos realizados em grupo, representando 46\% (05), em dupla com 36\% (04) e $18 \%$ (02) foram trabalhos individuais.

Com relação ao segundo indicador (instituição), com exceção de uma pesquisa desenvolvida em escola técnica, todas as demais foram desenvolvidas em instituições públicas de ensino superior. Todas as pesquisas foram desenvolvidas na região Sudeste do Brasil, sendo que apenas uma foi no Rio de Janeiro, as demais em São Paulo, correspondendo a $91 \%$ das pesquisas. Não foram encontrados estudos publicados em periódicos sediados nas demais regiões do país.

O terceiro indicador diz respeito ao objeto de estudo dos artigos, verificando-se que as pesquisas se desenvolveram em áreas diferenciadas, como Saúde Coletiva, Obstetrícia e Licenciatura em Enfermagem. Foram incluídos estudantes do curso de auxiliar de enfermagem (02), estudantes de enfermagem do ensino médio (01), docentes da disciplina de Enfermagem Psiquiátrica (01), e a maioria da população estudada foi de estudantes de graduação em Enfermagem, nas disciplinas de Enfermagem Materno-infantil e Enfermagem Psiquiátrica, inclusive uma pesquisa no estágio dessas disciplinas, e na disciplina Saúde da Mulher.

O quarto e o quinto indicadores são relativos às ferramentas utilizadas para melhorar o ensino e principais críticas ao ensino de Enfermagem, respectivamente. Nesses obteve-se como base a análise fenomenológica com o objetivo de "descrever a estrutura total da experiência vivida", incluindo o significado que estas experiências representam para os indivíduos que delas participam.

\section{DISCUSSÃO}

O grande percentual de autores com o título de doutor e do sexo feminino reforça a percepção do crescimento do número de mulheres realizando atividades científicas. Há uma nítida tendência do avanço dessas pesquisadoras na direção da maior qualificação e habilidades para participar soberanamente, e não de maneira co-responsável pela produção de um trabalho científico, nos grupos de pesquisas nacionais ${ }^{(7)}$.

A questão do ensino de Enfermagem está ligada à fenomenologia, esta não se ocupa da explicação, mas sim da compreensão do fenômeno ${ }^{(9)}$. Num dos artigos analisados reforça-se a necessidade de estudar um posicionamento a respeito de crenças, valores e relações de poder, e a compreensão crítica dos aspectos que integram o conjunto de habilidades que devem ser desenvolvidas pelos alunos ${ }^{(10)}$. Neste sentido, o processo psicopedagógico auxilia na formação, indo além dos ensinamentos científicos, descobrindo e valorizando a pessoa que existe dentro de cada profissional ${ }^{(11)}$.

Cabe mencionar que as práticas pedagógicas de Enfermagem até os anos 80, de acordo com a literatura, eram baseadas no simples cumprimento de regras, ou seja, posturas de disciplina, de obediência e de rígidos padrões éticos. Essas práticas contribuíram para formar profissionais acríticos, moldados e voltados para o 
tecnicismo, entretanto, algumas escolas ainda utilizam tais práticas. Um curso de Enfermagem que não tem a incumbência de alterar para melhor $\mathrm{o}$ atendimento que presta à sociedade, que não confronta os interesses profissionais da área de saúde e da sociedade, certamente estará formando profissionais descompromissados com as mudanças necessárias ${ }^{(10)}$.

Dentre os artigos que abordam o ensino de Enfermagem nas categorias de auxiliar e de técnico em enfermagem, um deles remete a análise do processo histórico de criação dos cursos, já na década de 40 , como proposta das enfermeiras brasileiras para atender à escassez de pessoal capacitado para o trabalho de Enfermagem, que era executado na grande maioria por pessoas leigas.

Os caminhos trilhados no passado foram contrários ao que o mercado de trabalho buscava. Atualmente, em todas as áreas, incluindo a de Enfermagem, o profissional deve ser crítico, capaz de buscar novos conhecimentos e de discutir democraticamente com sua equipe os problemas do cotidiano, as soluções destes e os resultados ${ }^{(12)}$. Um dos trabalhos aponta que a formação do profissional deve ser voltada para o cotidiano da assistência, quando afirma que a experiência do aluno, vivenciada nos postos de saúde da comunidade, explicita as necessidades de conhecimento para o exercício da profissão ${ }^{(9)}$.

Igualmente, o conhecimento produzido tem a incumbência de atender ao novo modelo e padrão que a sociedade exige, transmitido com criatividade e compromisso. Igualmente o aprendizado deve ser julgado, examinado, notando a perfeição ou os defeitos daquilo que se passa a conhecer, seja a respeito de crenças, valores e relações de poder ou a problemas assistenciais do cotidiano.

Portanto, as perspectivas do ensino de Enfermagem estão associadas à superação de obstáculos como a elaboração de novas estratégias pedagógicas, no campo de ação do ensino médio, da graduação e da pós-graduação, aptas a facilitar o fortalecimento da vocação, tanto para o serviço, quanto para a investigação e a docência ${ }^{(11)}$.

\section{CONSIDERAÇÕES FINAIS}

Pode-se perceber pelo presente estudo que a pesquisa científica na área do ensino de Enfermagem, em seus diversos níveis, ainda é pouco desenvolvida. Tal fato aponta para a necessidade de maiores estudos sobre a importância do processo histórico e os caminhos que a Enfermagem deve trilhar como categoria.

Com relação ao perfil dos autores dos artigos, estes possuem formação acadêmica adequada à reflexão no tema, em sua maioria representam os doutores em Enfermagem. Entretanto, percebeu-se a necessidade de novidades na transmissão da habilidade de criticar para alcançar a arte da educação e da instrução em Enfermagem.

O principal foco dos estudos são as mudanças sofridas e, em alguns, a necessidade de mudanças no ensino de Enfermagem para atender ao contexto econômico, político e social e às evoluções das políticas públicas de saúde ao longo do tempo. Ora, recomenda-se que essa discussão seja de caráter permanente, pois o processo ensino-aprendizagem na área da Enfermagem deve se manter ajustado à evolução dos saberes em todas as áreas e em todos os tempos.

\section{REFERÊNCIAS}

1. Ito EE, Peres AM, Takahashi RT, Leite MMJ. O Ensino de enfermagem e as diretrizes curriculares nacionais: utopia $\mathrm{x}$ realidade. Rev Esc Enferm USP. 2006;40(4):570-5.

2. Mourão LC, Martins RCB, Vieira CM, Rossin E, L'Abbate S. Análise institucional e educação: reforma curricular nas universidades pública e privada. Edu Soc. 2007;28(98):181-210.

3. Chaves E C. O desempenho de papéis sociais numa relação de ensino-aprendizado. Rev Latino-Am Enfermagem. 1993;1(n.esp):35-42.

4. Silva RM, Silva ICM, Ravalia RA. Ensino de enfermagem: reflexões sobre o estágio curricular supervisionado. Rev Práxis. 2009;1(1):37-41.

5. Ribeiro MILC, Pedrão LJ. Relacionamento interpessoal em enfermagem: considerações sobre formação/atuação no nível médio de enfermagem. Paidéia. 2001;11(21):99102.

6. Bousso RS, Merighi MABM, Rolim MA, Riesco MLG, Angelo M. Estágio curricular em enfermagem: transição de identidades. Rev Esc Enferm USP. 2000;34(2):218-25.

7. Borba ÉO, Neves EB. O perfil da produção científica em biossegurança no SciELO. Cad Saúde Colet. 2009;17(3):675-90.

8. Hayashi MCPI, Ferreira Junior A, Bittar M, Hayashi 
CRM, Silva MR. História da educação brasileira: produção científica na biblioteca eletrônica SCIELO. Edu Soc. 2008;29(102):181-211.

9. Merighi MAB, Bonadio IC. A vivência de alunos de graduação em enfermagem na assistência à saúde da mulher em uma comunidade de baixa renda: uma abordagem fenomenológica. Rev Esc Enferm USP. 1998;32(2):109-16.

10. Sanna MC. A evolução da disciplina de administração aplicada à enfermagem na escola de enfermagem da USP no período de 1980 a 1995. Rev Esc Enferm USP. 1999;33(1):17-30.

11. Esperidiao E, Munari DB, Stacciarin JMR. Desenvolvendo pessoas: estratégias didáticas facilitadoras para o autoconhecimento na formação do enfermeiro. Rev Latino-Am Enfermagem. 2002;10(4):516-22.

12. Padilha MICS, Borenstein MS. O método de pesquisa histórica na enfermagem. Texto \& Contexto Enferm. 2005;14(4):575-84. 